\title{
Characterization of rotenoid stemonal by semiempirical methods and molecular docking
}

\author{
Victor Moreira de Oliveira ${ }^{1}$ (D) Sandy Pereira Estácio ${ }^{1}$ (I) . Francisco Rogênio da Silva Mendes ${ }^{1}$ (D) \\ Othon Souto Campos ${ }^{3}$ (D) Márcia Machado Marinho² ${ }^{2} \cdot$ Emmanuel Silva Marinho' $^{1}$
}

Received: 28 October 2019 / Accepted: 26 February 2020 / Published online: 18 March 2020

(c) Springer Nature Switzerland AG 2020

\begin{abstract}
Clitoria fairchildiana is a common plant in Amazon rain forest. Popularly known as sombreiro, this plant has a great potential to use its phytochemical content for biological and medical applications. Stemonal, one of many phytochemical products extracted from "sobreiro", presents cytotoxic and anti-inflamatory activities, which means that has great potential for pharmaceutical applications. In order to collaborate with stemonal research, this paper studied the molecular properties of this molecule. The molecular structure of stemonal was optimized using semi-empiric methods, such as PM3, using ArgusLab ${ }^{\oplus}$ software. Molecular parameters, such as frontier orbitals (HOMO and LUMO), MESP and formation enthalpy were obtained. Also, molecular docking experiments were conducted in order to evaluate the applicability over $\mathrm{AChE}$, and the coupling of stemonal in this enzyme shows that the phytochemical binds into the catalytic site of the enzyme, which means that the molecule inhibits the hydrolysis of acethylcoline, the neurotransmitter evolved into skeletal muscules. Therefore, stemonal molecule has great potential to be applied into pharmaceutical formulations to achieve a better treatment for Alzheimer's diesease.
\end{abstract}

Keywords Rotenone $\cdot$ Stemonal $\cdot$ Semiempirical methods $\cdot$ Molecular modeling $\cdot$ Molecular docking

\section{Introduction}

The pharmaceutical industry, since decades ago had the idea to scientifically explore the relation between drug side effects and therapeutical efficency. For delivering a new drug into market, a 10-15 years gap and a substantial investiment of 500 million to 2 billion dollars, but statistics brought by US FDA showed a drug failure of $30 \%$ in early clinical tests associated with adverse side-effects [39]. Therefore, drug design can be very expensive and frustrating if the result showed to be unsatisfactory.

In this context, in silico methods, such as DFT modeling and molecular docking methods brings advantages, such as reduced research time for a molecule, computational details regarding the interaction between the molecule and a biological target (an enzyme, for example) and almost zero investiment for acquiring the software [5,24]. The most popular platforms, such as ORCA, ArgusLab and AutoDock Vina packages, are available for free to download in any computer, in any commercial available operational system [22, 23, 34-36].

Aside the computational molecular modeling solution, another important problem in drug development is the side effects brought by the drug. Some diseases, such as Chagas' and Alzheimer's diseases [1, 2, 20, 33], has pharmaceutical formulations that are proved to be efficient but the side effects are adverse. In this context, using phytochemical compounds are a tendency for both increasing

Othon Souto Campos, othon.campos@ufes.br|'Department of Chemistry, University State of Ceará, Limoeiro Do Norte, Ceará, Brazil. ${ }^{2}$ Departament of Pharmacy, Federal University of Ceará, Fortaleza, Ceará, Brazil. ${ }^{3}$ Chemistry and Physics Department, Federal University of Espírito Santo, Alegre, Espírito Santo, Brazil. 
the effectiveness of the drug and diminishing the side effects, once the popular knowledge of using vegetable products for pharmaceutical use is a tradition in many countries worldwide, including Brazil itself $[8,12]$. The harmony between phytochemical knowledge and computational experiments brings a broad view of applications that in vitro experiments cannot reach.

Regarding the potential of phytochemical compounds, an Amazonian plant commonly known as sombreiro (Clitoria fairchildiana) is very popular in Brazil $[4,7,9,18,28]$, once this kind of plant is common in large and open places, such as gardens, roads and national parks. Many papers show the activity of the phytochemical compounds extracted from sombreiro, such as stemonal that has cytotoxic [9], antioxidant [18], anti-inflammatory [28] applications towards many biological targets [29]. Although stemonal has higher phytochemical and pharmacological potential for many applications, no evidence for applying stemonal as an anti-Alzheimer's disease drug. The most important enzyme related with Alzheimer's disease is acethycolinesterase (AChE), which activity is increased due to the beta-amyloid deposits over the enzyme.

It is important to state that $\mathrm{AChE}$ is a very complex enzyme that drives part of the muscular neurotransmission, and AChE has basically two catalytic sites within its strutcutre [40]:

1. The known catalytic triad by H447, E334 and S203 residues,

2. And the extented catalytic site from Y337 residue.

The hydrolysis mechanism of AChE is based on acylation/deacylation of S203 residue towards protonation of H447 imidazolic ring, and the acyl group of acethylcoline bonds with S203 residue and choline releases from enzyme along the deprotonation of imidazolic ring. The second step is the capture of a proton from water and the hydroxyl ion reacts with carbonyl group of acethylated S203 residue, and the complex itself produces acetic acid and the regeneration of $\mathrm{S} 203$ and $\mathrm{H} 447$ residues from their initial structures [40]. Regarding the Alzheimer's disease, García-Ayllón and coworkers $[10,11]$ indicated that patitents with this disease had found altered levels of AChE in patient's blood plasma along with alterations in cholinesterase levels and presence of modified colinesterase such as butyrylcholinesterase, which is correlated with other neural disfunctions on human organism [11].

Although AChE is an enzyme, the molecule undergoes in other reactions, such as the irreversible inhibition of AChE by organophosphorate (OP) compounds like inseticides $[6,31]$. Due to the chemical structure of the catalytic sites of $A C h E$, they are avaliable for reaction with any central atom that is nucleophilic, once hydrolysis reaction occours by carbonyl group of the ester from acethylcolisterase, naturally AChE will react with those compounds due to nucleophylic nature of oxygen present in OP compounds. At the first step of AChE hydrolysis, S203 residue reacts with phosporous from $O P$, and a very stable adduct is produced and not possible to revert the reaction to the initial structure of S203. The equilibrium constant is very favorable, and the Gibbs energy is negative, almost $-100 \mathrm{~kJ} \mathrm{~mol}^{-1}$, showing that the AChE can undergo a competitive kinetics towards other molecules [31].

As it can be seen, the importance on studing AChE is crucial, and this paper shows an in silico characterization of rotenone stemonal by semi-empirical methods and studying its reactivity by frontier orbital analysis and further molecular docking analysis towards AChE enzyme.

\section{Methodology}

\subsection{Classical and quantum calculations}

All calculations were made in an Intel-based PC running Windows 10 in optimal configuration. The chemical structure of stemonal was acquired in Pubchem ${ }^{\circledast}$ repository (InChlkey INRSYSTZYGIZOF-UHFFFAFAYSA-N), and primary results regarding some physicochemical properties such as pKa using Calculator Plugins in MarvinSketch $\odot$ version 19.8.0, 2018, ChemAxon (https://www.chema xon.com) using Academic License. Calculations regarding molecular propriertes, such as optimization energy, electrostatic map, formation enthalpy and frontier orbitals were calculated using PM3 semiempirical method included in ArgusLab ${ }^{\circledR}$ version 4.0.1 [34]. The semiempirical calculations were made by doing 200 iterations per cycle for structure optimization until the minimum energy was achieved together with an optimized structure were both achieved. Also, a Mulliken charge calculaton was conducted in order to study the electrostatic charge distribution in stemonal molecule. To assess the molecular reactivity of stemonal, energy gap calculations were conducted as explained by Obot and coworkers [24].

\subsection{Molecular docking calculations}

Molecular docking calculations were performed using Avogadro (for drawing the molecular structure) [14], AutoDockVina (for running the molecular docking simulation) [36], AutoDockTools (for preparing the input files before running molecular docking) and UCSFChimera (for visualizing and taking out the results from molecular docking) [30]. Stemonal molecule was inserted in input file for AutoDockVina towards acethylcholinesterase enzyme (AChE, PDB code 4EY6 downloaded from https://www.rcsb.org/), 
and all ligands of $4 \mathrm{EY} 6$ enzyme were removed, once the PDB file contains some molecules that were used for crystallizing the enzyme. After removing them, the catalytic site was selected using a grid box that covered all those known residues of $A C h E$. All docking calculatons were validated by RMSD valules, which lied between 1,000 and $2,000 \AA$ [38].

\section{Results and discussions}

\subsection{Geometrical optimization and thermodynamical data}

The chemical structure of stemonal, like any chemical structure in many databases, is represented as pseudo-3D structure, and outer and inside covalent bondings are represented respectively, as wedged and dashed bounds. This representation does not bring the reality regarding the molecular structure. Therefore, an optimization in chemical structure of stemonal was performed in order to obtain the 3D structure with lowest energy, which means that those chemical structure is related with best correlation between potential energy and atom distance, as predicted by Lennard-Jones 6-12 law [25]. Figure 1 shows the planar and optimized 3D structural representations of stemonal.

The molecular optimization using PM3 semiempirical method allows to bring a more realistic approach for chemical studies, once the molecule has many different hybridizations and the molecular geometry should be achieved. Therefore, other properties such as formation enthalpy takes into account the optimized geometry. The calculated optimized energy was $-112.45 \mathrm{kcal} \mathrm{mol}$ -1 , and the calculated formation enthalpy of stemonal was $-254.50 \mathrm{kcal} \mathrm{mol}^{-1}$, indicating that the biochemical synthesis of stemonal is exergonic. The pKa value of stemonal is 7.28 , meaning that the molecule deprotonates in a slightly basic medium, and the calculation revelaled that the $-\mathrm{OH}$ group in phenolic ring contributes to molecule deprotonation, once this site is the only available site. Also, the calculated dipole moment vector was, in $(X ; Y ; Z)$ directions in debye, $(-1.08 ; 2.49 ; 2.76)$, and the resultant dipole moment vector was 3.87 debye, which corresponds to a very polar molecule if compared with the same dipole moment vector of water, 3.44 debye [15].

\subsection{Mulliken populational analysis and frontier orbitals study}

In order to study the electrostatic properties of stemonal, a Mulliken population analysis were conducted and the values are shown in Table 1.

Naturally, oxygen atoms are the second most electronegative atoms in periodic table, and this fact is confirmed by the higher value of charge (in modulus) if compared with some hydrogen and carbon atoms [15]. Although the charges are affected by oxygen electronegativity, their bonded hydrogen atoms bring also a relative higher value of positive charge, once this partial charge is a counterpart of the oxygen electronegativity effect over hydrogen atoms. Also, the hydrogen atoms bonded in aromatic ring also shows a relative higher positive charge, once the double bonds of the benzene polarizes the carbon atoms, creating a negative charge by resonance (as seen in negative charge in benzene's carbon atoms) and occupying the LUMO orbitals of the carbon, once the aromatic ring has $\mathrm{sp}^{2}$ hybridization, and the $\pi$ bonding can receive a lone pair of electrons. As mentioned earlier, the oxygen affects the charge over hydrogen atoms, and also over carbon atoms by the same electronegativity principle. Therefore, the hydrogen atoms bonded in carbon atoms that are bonded in oxygen atoms also suffer a minor charge change by a field effect if we consider the atoms of stemonal molecule as punctual charges and Couloumb law

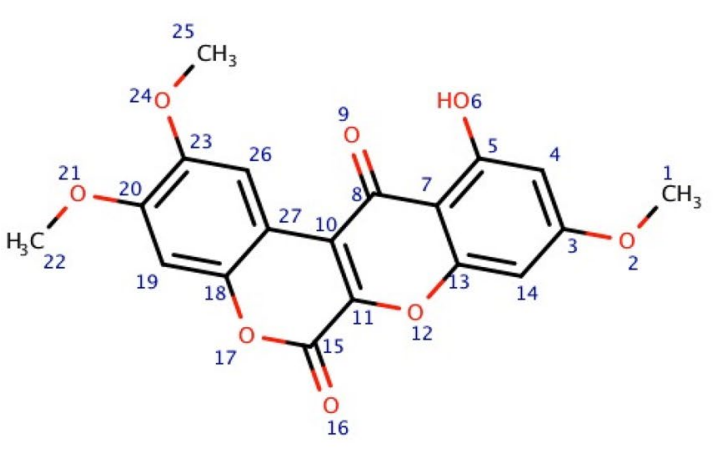

(A)

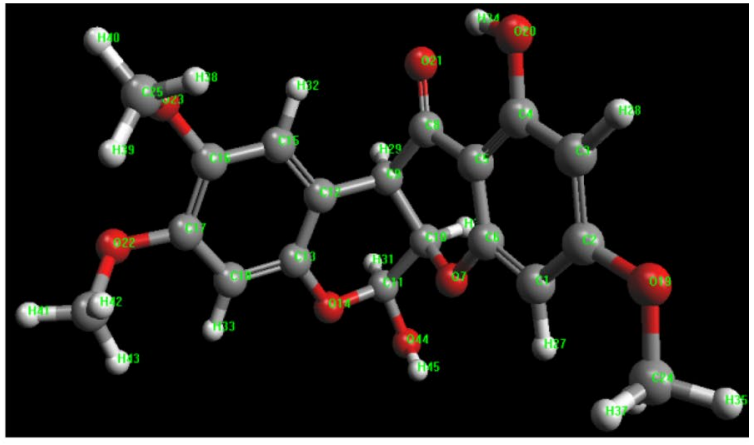

(B)

Fig. 1 Planar (a) and 3D (b) representations of stemonal 
Table 1 Individual atomic charges for stemonal molecule by Mulliken populational analysis. All atom numbers are related with PM3 calculation numbering, as shown in Fig. $1 \mathrm{~b}$

\begin{tabular}{lccc}
\hline Atom & Charge $(\mathrm{C})$ & Atom & Charge $(\mathrm{C})$ \\
\hline $01 \mathrm{C}$ & -0.4015 & $24 \mathrm{C}$ & -0.1533 \\
$02 \mathrm{C}$ & 0.214 & $25 \mathrm{C}$ & -0.1431 \\
$03 \mathrm{C}$ & -0.3678 & $26 \mathrm{C}$ & -0.1448 \\
$04 \mathrm{C}$ & 0.2697 & $27 \mathrm{H}$ & 0.2368 \\
$05 \mathrm{C}$ & -0.433 & $28 \mathrm{H}$ & 0.2496 \\
$06 \mathrm{C}$ & 0.2506 & $29 \mathrm{H}$ & 0.1886 \\
$07 \mathrm{O}$ & -0.1882 & $30 \mathrm{H}$ & 0.1606 \\
$08 \mathrm{C}$ & 0.4098 & $31 \mathrm{H}$ & 0.1524 \\
$09 \mathrm{C}$ & -0.173 & $32 \mathrm{H}$ & 0.2315 \\
$10 \mathrm{C}$ & -0.0715 & $33 \mathrm{H}$ & 0.2316 \\
$11 \mathrm{C}$ & 0.141 & $34 \mathrm{H}$ & 0.2837 \\
$12 \mathrm{C}$ & -0.1706 & $35 \mathrm{H}$ & 0.123 \\
$13 \mathrm{C}$ & 0.1276 & $36 \mathrm{H}$ & 0.0978 \\
$14 \mathrm{O}$ & -0.2143 & $37 \mathrm{H}$ & 0.1009 \\
$15 \mathrm{C}$ & -0.158 & $38 \mathrm{H}$ & 0.0868 \\
$16 \mathrm{C}$ & 0.0132 & $39 \mathrm{H}$ & 0.0901 \\
$17 \mathrm{C}$ & 0.0879 & $40 \mathrm{H}$ & 0.1157 \\
$18 \mathrm{C}$ & -0.2693 & $41 \mathrm{H}$ & 0.119 \\
$19 \mathrm{O}$ & -0.1888 & $42 \mathrm{H}$ & 0.0877 \\
$20 \mathrm{O}$ & -0.2636 & $43 \mathrm{H}$ & 0.0913 \\
$21 \mathrm{O}$ & -0.3675 & $44 \mathrm{O}$ & -0.3107 \\
$22 \mathrm{O}$ & -0.1913 & $45 \mathrm{H}$ & 0.2386 \\
$23 \mathrm{O}$ & -0.1894 & & \\
\hline & & &
\end{tabular}

being obeyed [15]. Therefore, this charge difference can bring some evidence on chemical reactivity if we consider Lewis acid-base theory [16], considering molecular sites that are nucleophilic and electrophilic in stemonal molecule. This fact can be seen in Fig. 2.
As it can be seen in Fig. 2, the $-\mathrm{CH}_{3}$ far ends of the stemonal molecule has the highest positive charge in molecule (white map scale), which can be classified as potential electrophilic sites for chemical reactions, and the aromatic rings together with oxygen atoms bonded in $-\mathrm{CH}_{3}$ and -H groups, due to its higher density charge as discussed earlier, can be associated with potential nucleophilic sites for chemical reactions (blue-to-red map scale). Although the electrostatic map shows potential regions for chemical reactions, a frontier orbitals study (also known as HOMO/ LUMO analysis) can be associated with electrostatic map results to have a better view of potential chemical reaction sites of the stemonal molecule, Fig. 3 shows the frontier orbitals of stemonal.

Figure 3 shows the localization of HOMO and LUMO in stemonal molecule. The HOMO surfaces (Fig. 3a) are localizes at the phenolic ring that bons two methoxy groups. This is reasonable once the aromatic ring receives electron density from methoxy groups, once they are known as aromatic rings activators for ortho and para electrophyllic substitution [3] Also, the non-bonding electrons from oxygen from methoxy groups and lactone ring makes part of HOMO surface as a pure $p$ orbital. The LUMO surfaces lies on the other side of the molecule, from $s p^{2}$ carbons from phenolylic ring and oxygen atoms in carbonyl group on the neighbor non-aromatic ring. This also is reasonable once the resonance structures arise from remotion of the lone pair from carbonyl group, and the phenolyic ring contributes to the molecule stabilization donating the $\pi$ electrons located at the benzene ring [3]. Therefore, the vacancy from resonance brings the LUMO from this region.

In order to study the reactivity arose from frontier orbitals, calculatons regarding the HOMO and LUMO energies were conducted, and Table 2 shows the results of those calculations as suggested by Obot and coworkers [24].
Fig. 2 Potential electrostatic map of stemonal molecule created by applying the Mulliken charges with scale

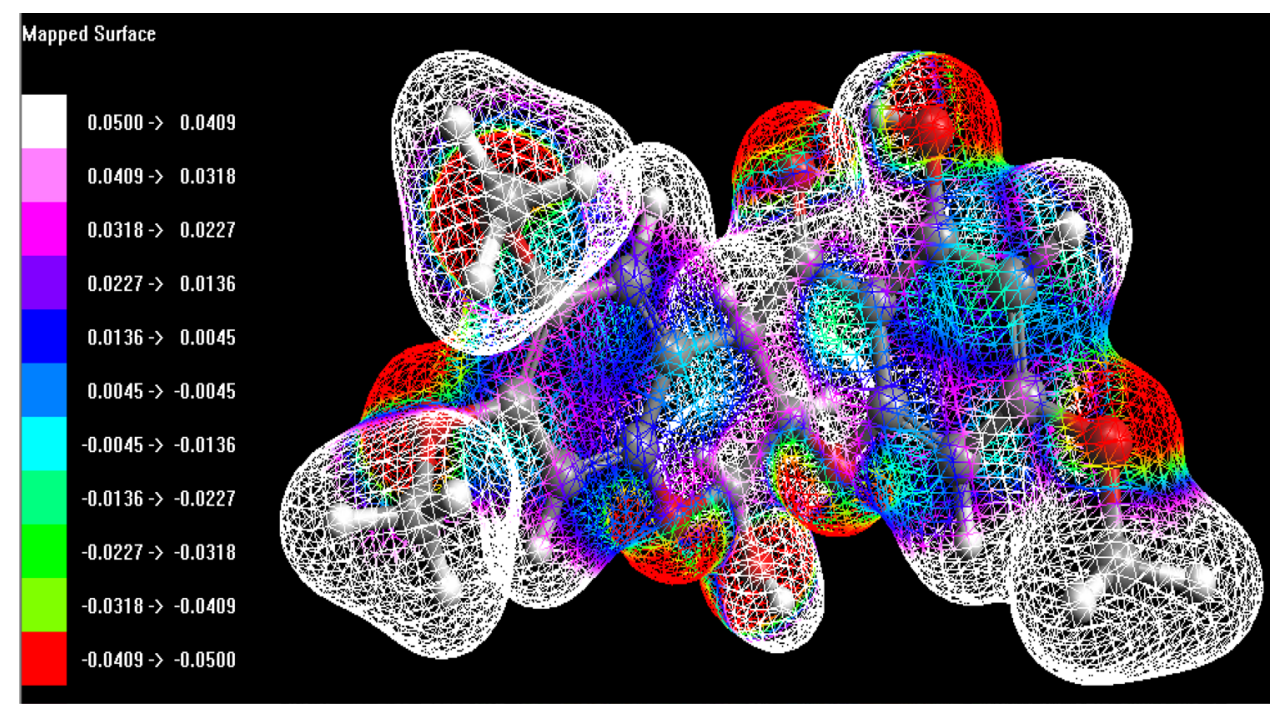




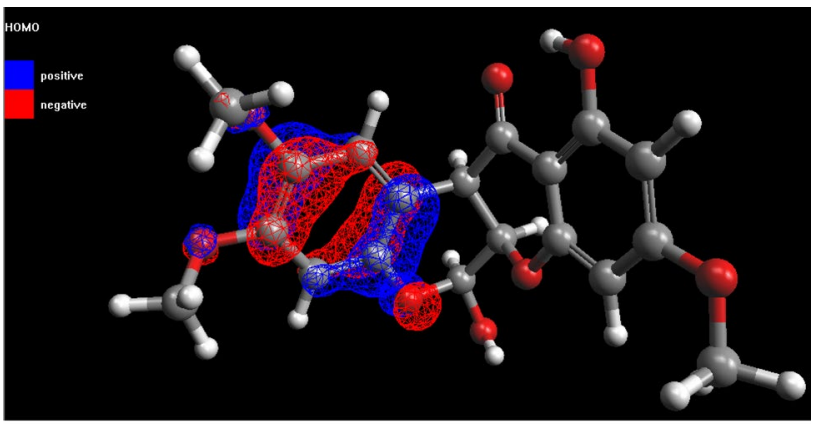

(A)

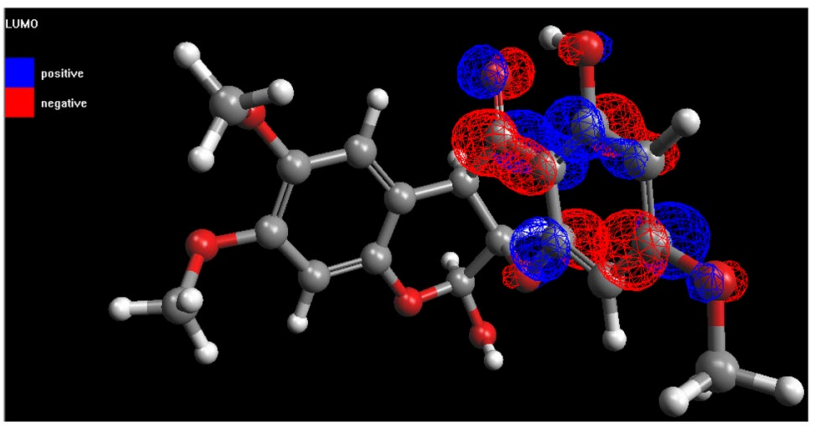

(B)

Fig. 3 HOMO (a) and LUMO (b) surfaces over stemonal molecule

Table 2 HOMO and LUMO parameters for stemonal calculation

\begin{tabular}{ll}
\hline Propriety & Value \\
\hline $\mathrm{E}_{\mathrm{HOMO}}=-$ lonization energy & $-0.340 \mathrm{eV}$ \\
$\mathrm{E}_{\mathrm{LUMO}}=-$ Electron affinity & $-0.030 \mathrm{eV}$ \\
$\Delta \mathrm{E}_{\text {gap }}$ & $0.310 \mathrm{eV}$ \\
Global hardness & $0.155 \mathrm{eV}$ \\
Global softness & $6.452 \mathrm{eV}^{-1}$ \\
\hline
\end{tabular}

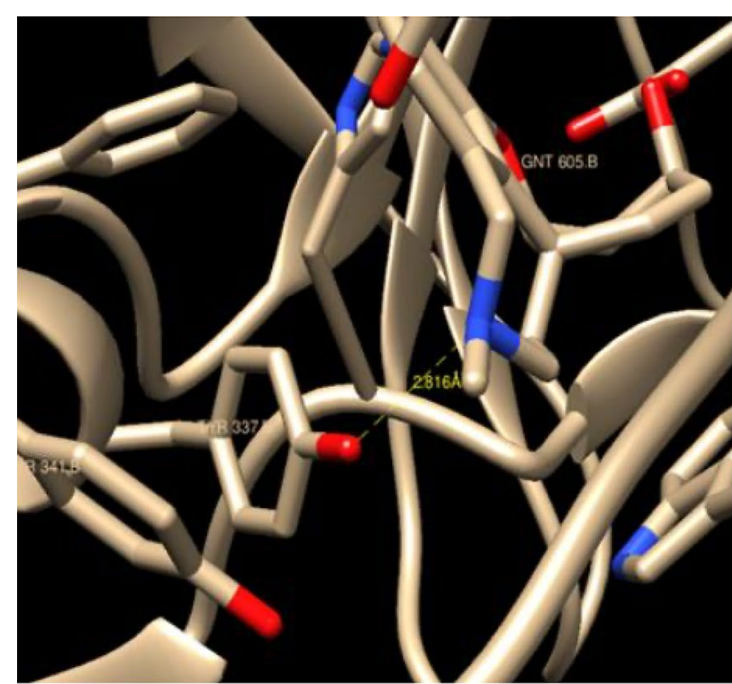

(A)
Table 2 shows the calculated HOMO and LUMO energies for stemonal molecule. As it can be seen, the molecule has a similar energy gap if compared with other molecules, such as neochlorogenic acid, $0.299 \mathrm{eV}$, but lower than other molecules such as aminacids (more than $4.0 \mathrm{eV}$ ). This fact is directly related to the reactivity of the molecule: once the gap difference between HOMO and LUMO orbitals is small, the molecule tends to donate electron density as a nucleophilic substance [16]. Otherwise, stemonal has the ability to receive electron density to occupy the LUMO orbitals as an electrophilic substance. Therefore, the small gap energy shows the electron density could run both frontier orbitals once the distance between HOMO and LUMO are small, and the electron density can be easily promoted from HOMO to LUMO. As it can be seen by hardness value, the global hardness is small but global softness is high. Taking into account the HSAB theory [26, 27, 37], it is easier to the molecule to donate electron density than receiving it, although gap energy is small. As it can be seen in Fig. $4 a$, b, the fraction of the frontier orbitals is different, being in qualitative terms, the HOMO surface larger than LUMO surface. Therefore, although gap energy tends to believe that stemonal works as an electron density donorreceptor, the HOMO surface shows, together with HSAB explanation, that stemonal has higher potential to be a nucleophilic (or electron density donor) than a electrophilic (or electron density receptor) substance; This fact agrees with experimental results regarding the antioxidant properties of stemonal elsewhere $[18,28]$.

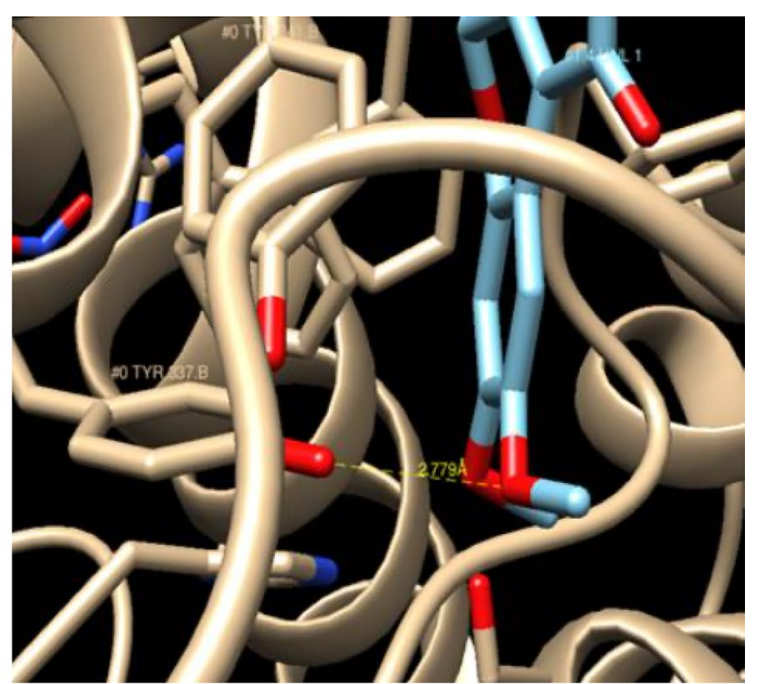

(B)

Fig. 4 Molecular distance (in $\AA$ ) between AChE and galantamine (a) and stemonal (b) 


\subsection{Molecular docking results}

The results regarding the molecular docking of rotenone over AChE is shown in Fig. 4.

Being galantamine the main drug for Alzheimer's disease treatment [2,21], this ligand can be considered the default value of docking over AChE to compare with stemonal. Being TYR 337 one of the catalytic residues of $A C h E$, the distance between galantamine and AChE is $2.816 \AA$ (Fig. 4a) while stemonal lies on a distance of $2.779 \AA$ of TYR 337 residue. Also, the score energy due to interaction between stemonal and AChE was $-8.3 \mathrm{kcal} \mathrm{mol}^{-1}$ (or $-35 \mathrm{~kJ} \mathrm{~mol}^{-1}$ ), and this energy is a Gibbs adsorption energy by definition [36]. Therefore, the interaction between stemonal and AChE is thermodynamically favorable, or this means that stemonal can block the enzymatic reaction of hydrolysis of acethylcoline to acethyl and coline, as shown by Fig. $5[2,19]$.

Once acethylcoline is a neurotransmisser, the intense activity of AChE in diagnosed Alzheimer's disease patients is higher if compared with healthy individuals, and the hydrolysis of acethylcoline interrupts the synaptic functioning of the neuronal cells $[2,13,33]$. Therefore, catalytic inhibition of the AChE is the goal for Alzheimer's disease to stop the AChE activity towards acethylcoline hydrolysis, and stemonal showed to block the TYR 337 residue related to the catalytic site of the hydrolysis reaction of acethylcoline. In order to investigate the nature of chemical bonding between other residues and stemonal molecule, Fig. 6 shows the calculated interactions in molecular docking of stemonal over AChE.

Figure 6 shows the interaction of stemonal among other residues. Most of them are conventional hydrogen bond, once TYR and PHE has polar-OH groups in their structures and interacts by this kind of bonding. TRP has an aromatic ring together with an indol ring, which brings a non-polar interaction with stemonal. Therefore, having lone $\pi$ electrons in both stemonal and TRP, both interacts directly in $\pi-\pi$ stacking interaction, when the TRP molecule goes planar with stemonal molecule. Although stemonal is a very polar molecule, the presence of aromatic rings in its structure

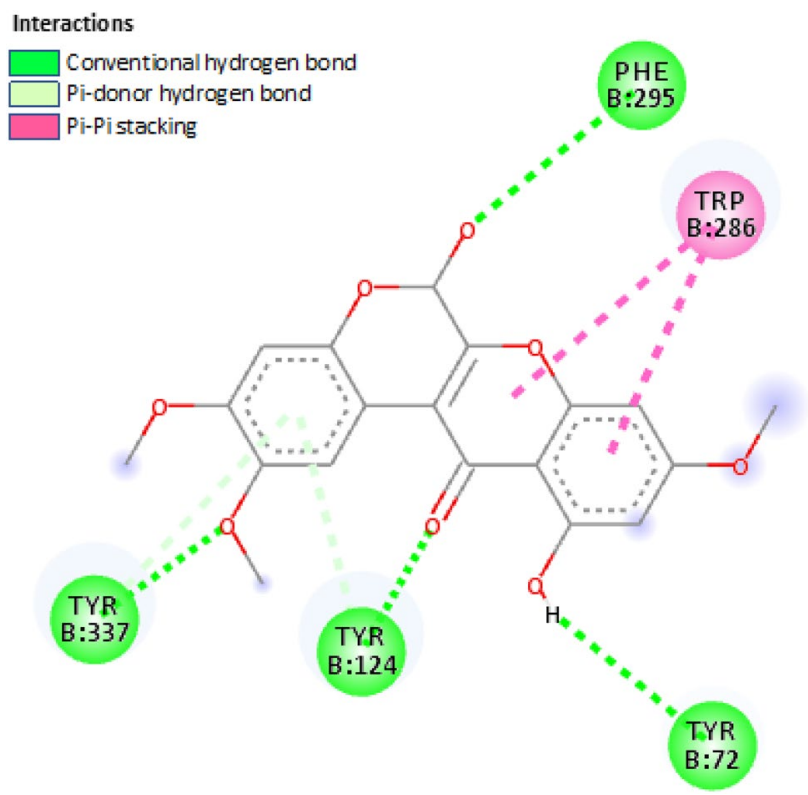

Fig. 6 Intermolecular interactions between stemonal and other residues of $\mathrm{AChE}$

brings a non-polarity that interacts with $\mathrm{AChE}$ enzyme. To summarize the docking results, Table 3 shows a resume of the results following Imberty and coworkers interaction of hydrogen bonding and bonding force [17].

Table 3 shows the results' summary for molecular docking of both stemonal and galantamine. As it can be seen, stemonal interacts strongly by hydrogen bonding between oxygen and hydrogen atoms, as galantamine does in docking. Therefore, the stemonal molecule has, at least potentially, a strong bonding towards AChE residues by hydrogen bonding, as galantamine does. Until this date, a doctorate thesis [32] showed stemonal inhibited AChE enzyme along other similar molecules, such as clitoriacetal and 6-deoxiclitoriacetal, but stemonal had the smaller inhibition if compared with other rotenones, but this experimental data already shows a biochemical activity towards AChE.

Fig. 5 Acetylcholine hydrolysis reaction by $A C h E$
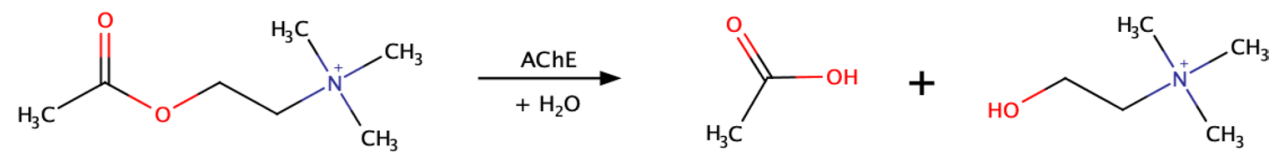

Table 3 Results from stemonal docking towards AChE docking

\begin{tabular}{llllll}
\hline Molecule & Residue & Distance $(\AA)$ & $\begin{array}{l}\text { Score energy } \\
\left.(\mathrm{kJ} \mathrm{mol})^{-1}\right)\end{array}$ & Bonding type & Bonding strength \\
\hline Stemonal & 337 & 2.779 & -35 & Conventional hydrogen bonding & Strong \\
Galantamine & & 2.816 & - & & Strong \\
& & $($ from PDB file) & & & \\
\hline
\end{tabular}




\section{Conclusions}

Stemonal molecule showed to be a polar molecule with low reactivity due to the small gap energy between frontier orbitals. Electrostatic map results showed high nucleophlic sites on oxygen atoms of the molecule, having their HOMO surface over the aromatic ring bonded with methoxyl groups, and the LUMO surface was found in the other side of the molecule, in the phenolyic ring. Stemonal also showed to have a small hardness but elevated softness in terms of HSAB theory, which agrees with antioxidant results found in literature. Also, stemonal links over the catalytic site of AChE, proving to be a potential molecule for using in antiAlzheimer's disease medicine.

Acknowledgments This work was partly supported by National Council for Scientific and Technological Development (CNPq) and Coordenação de Aperfeiçoamento de Pessoal de Nível SuperiorBrasil (CAPES) -Finance Code 001 The authors want to thank State University of Ceará (PROPGPQ/UECE) for financial and infrastructure support.

\section{Compliance with ethical standards}

Conflict of interest The authors declare no interest conflict in this paper.

\section{References}

1. Arendash GW, Schleif W, Rezai-Zadeh K, Jackson EK, Zacharia LC, Cracchiolo JR, Shippy D, Tan J (2006) Caffeine protects Alzheimer's mice against cognitive impairment and reduces brain beta-amyloid production. Neuroscience 142:941-952. https:// doi.org/10.1016/j.neuroscience.2006.07.021

2. Cheung J, Rudolph MJ, Burshteyn F, Cassidy MS, Gary EN, Love J, Franklin MC, Height JJ (2012) Structures of human acetylcholinesterase in complex with pharmacologically important ligands. J Med Chem 55:10282-10286. https://doi.org/10.1021/ jm300871x

3. Clayden J, Greeves N, Warren SG (2012) Organic chemistry, 2nd edn. Oxford University Press, Oxford

4. Coelho KP, Ribeiro PRDA, de Moura EG, Aguiar ADCF, Rodrigues TL, Moreira FMDS (2018) Symbiosis of rhizobia with Gliricidia sepium and Clitoria fairchildiana in an Oxisol in the pre-Amazon region of Maranhão State. Acta Sci Agron 40:35248. https://doi. org/10.4025/actasciagron.v40i1.35248

5. Conradie J (2015) A Frontier orbital energy approach to redox potentials. In: Journal of physics: conference series, p 012045

6. Coppage DL (1972) Organophosphate pesticides: specific level of brain AChE inhibition related to death in sheepshead minnows. Trans Am Fish Soc 101:534-536. https ://doi.org/10.1577/1548-8659\%281972\%29101\%3C534 \%3АOP\%3E2.0.CO\%3B2

7. Dantzger M, Vasconcelos IM, Scorsato V, Aparicio R, Marangoni S, Macedo MLR (2015) Bowman-Birk proteinase inhibitor from Clitoria fairchildiana seeds: Isolation, biochemical properties and insecticidal potential. Phytochemistry 118:224-235. https://doi. org/10.1016/J.PHYTOCHEM.2015.08.013
8. Das A, Chaudary SK, Bhat HR, Shakya A (2018) Cupea carthagenensis: a review of its ethnobotany, pharmacology and phytochemistry. Bull Arunachal For Res 33:1-14

9. David JM, Santos RAF, Ferreira AS, David JP, Fontana R (2018) Atividade antifúngica dos rotenoides das sementes e raiz de Clitoria fairchildiana. Rev Fitos. https://doi.org/10.5935/24464775.20180008

10. García-Ayllón M-S, Riba-Llena I, Serra-Basante C, Alom J, Boopathy R, Sáez-Valero J (2010) Altered levels of acetylcholinesterase in Alzheimer plasma. PLoS ONE 5:e8701. https://doi. org/10.1371/journal.pone.0008701

11. García-Ayllón M-S, Small DH, Avila J, Sáez-Valero J (2011) Revisiting the role of acetylcholinesterase in alzheimer's disease: crosstalk with P-tau and $\beta$-amyloid. Front Mol Neurosci 4:22. https:// doi.org/10.3389/fnmol.2011.00022

12. Gontijo DC, Nascimento MFA, do Brandão GC, de Oliveira $A B$ (2019) Phytochemistry and antiplasmodial activity of Xylopia sericea leaves. Nat Prod Res. https://doi.org/10.1080/14786 419.2019.1577838

13. Grossberg GT (2003) Cholinesterase inhibitors for the treatment of Alzheimer's disease: getting on and staying on. Curr Ther Res 64:216-235. https://doi.org/10.1016/S0011-393X(03)00059-6

14. Hanwell MD, Curtis DE, Lonie DC, Vandermeersch T, Zurek E, Hutchison GR (2012) Avogadro: an advanced semantic chemical editor, visualization, and analysis platform. J Cheminform 4:17. https://doi.org/10.1186/1758-2946-4-17

15. Herring GE, Petrucci RH, Harwood WS, Madura J (2007) General chemistry: principles \& modern applications, 9th edn. Pearson Education Inc, New Jersey

16. House J (2013) Inorganic chemistry, 2nd edn. Academic Press, Cambridge

17. Imberty A, Hardman KD, Carver JP, Perez S (1991) Molecular modelling of protein-carbohydrate interactions. Docking of monosaccharides in the binding site of concanavalin A. Glycobiology 1:631-642. https://doi.org/10.1093/glycob/1.6.631

18. Leite JFM, Assreuy AMS, Mota MRL, de Bringel PH, SF, e Lacerda RR, Gomes V de M, Cajazeiras JB, do Nascimento KS, Pessôa H de LF, Gadelha CA de A, Delatorre P, Cavada BS, Santi-Gadelha T (2012) Antinociceptive and anti-inflammatory effects of a lectinlike substance from Clitoria fairchildiana R. Howard Seeds Mol 17:3277-3290. https://doi.org/10.3390/molecules 17033277

19. Lilienfeld S (2006) Galantamine-a novel cholinergic drug with a unique dual mode of action for the treatment of patients with Alzheimer's disease. CNS Drug Rev 8:159-176. https://doi. org/10.1111/j.1527-3458.2002.tb00221.x

20. Maelicke A, Albuquerque EX (2000) Allosteric modulation of nicotinic acetylcholine receptors as a treatment strategy for Alzheimer's disease. Eur J Pharmacol 393:165-170. https://doi. org/10.1016/S0014-2999(00)00093-5

21. Maelicke A, Hoeffle-Maas A, Ludwig J, Maus A, Samochocki M, Jordis U, Koepke AKE (2010) Memogain is a galantamine prodrug having dramatically reduced adverse effects and enhanced efficacy. J Mol Neurosci 40:135-137. https://doi.org/10.1007/ s12031-009-9269-5

22. Neese $F(2012)$ The ORCA program system. Wiley Interdiscip Rev Comput Mol Sci 2:73-78. https://doi.org/10.1002/wcms.81

23. Neese $F(2018)$ Software update: the ORCA program system, version 4.0. Wiley Interdiscip Rev Comput Mol Sci 8:e1327. https ://doi.org/10.1002/wcms.1327

24. Obot IB, Macdonald DD, Gasem ZM (2015) Density functional theory (DFT) as a powerful tool for designing new organic corrosion inhibitors. Part 1: An overview. Corros Sci 99:1-30. https ://doi.org/10.1016/J.CORSCI.2015.01.037

25. Paquet E, Viktor HL (2015) Molecular dynamics, Monte Carlo Simulations, and Langevin dynamics: a computational review. 
Biomed Res Int 2015:1-18. https://doi.org/10.1155/2015/18391 8

26. Pearson RG (1985) Absolute electronegativity and absolute hardness of Lewis acids and bases. J Am Chem Soc 107:68016806. https://doi.org/10.1021/ja00310a009

27. Pearson RG (2005) Chemical hardness and density functional theory. J Chem Sci 117:369-377. https://doi.org/10.1007/BF027 08340

28. Pereira da Silva B, Paz Parente J (2002) Antiinflammatory activity of rotenoids from Clitoria fairchildiana. Phyther Res 16:87-88. https://doi.org/10.1002/ptr.807

29. Perveen S, Yang S, Meng M, Xu W, Zhang G, Fang X (2019) Asymmetric total synthesis of rotenoids via organocatalyzed dynamic kinetic resolution. Commun Chem 2:8. https://doi.org/10.1038/ s42004-019-0110-y

30. Pettersen EF, Goddard TD, Huang CC, Couch GS, Greenblatt DM, Meng EC, Ferrin TE (2004) UCSF chimera-a visualization system for exploratory research and analysis. J Comput Chem 25:1605-1612. https://doi.org/10.1002/jcc.20084

31. Quinn DM, Topczewski J, Yasapala N, Lodge A (2017) Why is aged acetylcholinesterase so difficult to reactivate? Molecules 22:1464. https://doi.org/10.3390/molecules22091464

32. Santos RAF (2014) Estudo fitoquímico e avaliação biológica dos flavonoides isolados de clitoria fairchildiana R. Instituto de Química - Federal University of Bahia, A. Howard

33. Solas M, Puerta E, Ramirez JM (2015) Treatment options in Alzheimer's disease: the GABA story. Curr Pharm Des 21(12):4960-4971

34. Thompson MA (2004) Molecular docking using ArgusLab: an efficient shape-based search algorithm and an enhanced XScore scoring function. In: The 228th ACS national meeting. American Chemical Society, Philadelphia

35. Trott O, Olson A (2010) NIH public access. J Comput Chem 31:455-461. https://doi.org/10.1002/jcc.21334.AutoDock

36. Trott O, Olson AJ (2009) AutoDock Vina: Improving the speed and accuracy of docking with a new scoring function, efficient optimization, and multithreading. J Comput Chem. https://doi. org/10.1002/jcc.21334

37. Yang W, Parr RG (1985) Hardness, softness, and the fukui function in the electronic theory of metals and catalysis. Proc Nati Acad Sci USA 82:6723-6726

38. Yuriev E, Holien J, Ramsland PA (2015) Improvements, trends, and new ideas in molecular docking: 2012-2013 in review. J Mol Recognit 28:581-604. https://doi.org/10.1002/jmr.2471

39. Zhang P, Wang F, Hu J, Sorrentino R (2013) Exploring the relationship between drug side-effects and therapeutic indications. AMIA Annu Symp Proc 2013:1568-1577

40. Zhou Y, Wang S, Zhang Y (2010) Catalytic reaction mechanism of acetylcholinesterase determined by born-oppenheimer ab initio QM/MM molecular dynamics simulations. J Phys Chem B 114:8817-8825. https://doi.org/10.1021/jp104258d

Publisher's Note Springer Nature remains neutral with regard to jurisdictional claims in published maps and institutional affiliations. 